\title{
Organizing Primary Care for an Integrated System
}

\author{
LEAD PAPER \\ $\propto$ \\ Walter W. Rosser, MD, MRCGP(UK), CCFP, FCFP \\ President, The Ontario College of Family Physicians \\ Jan Kasperski, RN, MHSc, CHE \\ Executive Director, The Ontario College of Family Physicians
}

DURING THE PAST DECADE, many changes have occurred in the Canadian healthcare delivery system but few, if any, of these changes have specifically addressed the role of the family physician.

This paper proposes a number of changes to the infrastructure that supports the role of family physicians, including family physician accountability for delivering twenty-four-hour, seven-days-per-week services to a defined population of patients. The infrastructure needed to support family physicians as the coordinators of care across the continuum of healthcare services includes family-medicine group practices or practice networks linked by electronic networks. Family medicine is the key to health-system integration. Systems to integrate family medicine with other primary healthcare providers and with secondary- and tertiary-care systems are proposed, as well as quality-improvement systems for family medicine. 
Implementation of these strategies is essential in the transition to a fully integrated healthcare system and is an important part of making the Canadian system of healthcare sustainable.

\section{Introduction}

During the past few years, there has been a great deal of rhetoric about the importance of primary care as the cornerstone of the healthcare system. The recognition of the importance of primary care has led to a variety of reviews suggesting reform and integration to strengthen the role of primary healthcare. Nine reports over the past five years have discussed various strategies for reform (PCCCAR 1996). There has been a surprising level of agreement in all nine reports regarding the changes needed. In spite of a growing consensus, little action has been taken to modify and improve primary-healthcare delivery in any province. This is not to say that change has not happened. There have been major impacts on family physicians and their patients as a "side effect" of rationalization, regionalization and hospital restructuring, which have been the main focus of reform to date. In Ontario, hospital restructuring and subsequent lack of community-based services have directly affected the delivery of family-medicine services. Hospital reform was not planned carefully enough to prevent this negative impact, and the changes have tended to go in the opposite direction to the strategies presented in the nine primary-care reform reports (OCFP 1999a).

This lack of attention to primary care, and family medicine in particular, is somewhat surprising given the importance of family physicians in the Canadian healthcare system. Canada is highly regarded internationally for the strength of its primary-care system (Starfield 1998). Compared to most developed countries, Canada has one of the highest percentages of family doctors relative to consultants. Family physicians are the principal healthcare providers of medical care at the primary-care level; $50 \%$ of Canada's physicians are family physicians. The most likely reason for delays in reforming the primarycare system is lack of political will, for any change in healthcare delivery at the primary level will affect the entire population. The scope of family practice means that even minor changes will be likely to raise the ire of various interest groups and will be politically risky. These are 
risks that need to be taken, however, for the maintenance and improvement of healthcare delivery in Canada (OCFP 1999b).

\section{Problems Identified with the Delivery of Primary Care}

Although the government continues to deny there is any shortage of physicians, there is a growing shortage throughout the province of Ontario. Most other provinces are also experiencing shortages. The supply of family physicians in Ontario has been dramatically reduced since the early 1980s when over 1000 new family practitioners were licensed to practise annually. Fewer than 190 family physicians were licensed in 1997 (CPSO 1999).

The hospital-based system has traditionally provided back-up whenever service needs overwhelm the primary-care delivery system. This is no longer the case. Rather, the primary-care system is now providing back-up for a down-sizing hospital system, with an everexpanding number of community-based organizations trying to fill the gap. The current climate is one of accelerating fragmentation in the delivery of care as the number of agencies increase without any coordination or organizational structure to support primary-care delivery. Although some steps have been taken to integrate key components of the system, namely, home care and long-term care through Community Care Access Centres, there remain few incentives to overcome the fragmentation that exists among community-based care providers and between the community and hospital sectors.

The essence of family medicine is the doctor/patient relationship. Table 1 demonstrates that the current fragmented healthcare system diminishes that relationship, with other providers of care delivering services in the absence of this vital therapeutic relationship. A prime example of the disconnection between family physicians and their patients in the current system can be seen in reviewing a patient's health record, which may reside in part with five to ten different organizations. In spite of high investments in information technology in the hospital sector, there are only one or two isolated examples of hospital systems providing outreach into the community (OCFP 1999c).

In both the community and hospital sectors, there is a general 
lack of understanding of the role of the family physician and of his or her value to the system. The four principles of family medicine, developed by the College of Family Physicians of Canada, provide a framework for the delivery of excellent healthcare. Table 2 describes these four principles, which commit each family physician to ensuring continuity of care across the continuum of healthcare services and throughout the life cycle, from birth to grave. The four principles speak to the key role of the family physician in our healthcare system and to the high level of skill needed to deliver comprehensive care to patients and their families.

The most important role of the family physician in today's environment is the identification and early diagnosis of problems. This requires a high degree of skill that is neither understood nor appreciat-

\begin{tabular}{|c|c|c|}
\hline ACCOUNTABILITY & PROVIDER OF CARE & $\begin{array}{l}\text { MAINTENANCE OF } \\
\text { DOCTOR/PATIENT RELATIONSHIP }\end{array}$ \\
\hline Family physician & Family practice visit & $\begin{array}{l}\text { - FP/patient relationship is } \\
\text { maintained and enhanced. }\end{array}$ \\
\hline Specialist & Specialist & $\begin{array}{l}\text { - FP coordinates access to specialist. } \\
\text { - FP/patient relationship may be splintered } \\
\text { as patient develops relationship with } \\
\text { specialist; relationship with specialist is } \\
\text { usually for one condition/health } \\
\text { problem only. }\end{array}$ \\
\hline On-call M.D. & Walk-in clinic & $\begin{array}{l}\text { - FP/patient relationship is splintered. } \\
\text { - Patient develops relationship with } \\
\text { different physician each visit. }\end{array}$ \\
\hline $\begin{array}{l}\text { Patient care } \\
\text { access coordinator }\end{array}$ & $\begin{array}{l}\text { Home care/ } \\
\text { community } \\
\text { services }\end{array}$ & $\begin{array}{l}\text { - FP/patient relationship usually } \\
\text { maintained. but approach to care } \\
\text { between FP and providers may not be } \\
\text { coordinated effectively. }\end{array}$ \\
\hline $\begin{array}{l}\text { Most responsible } \\
\text { physician }\end{array}$ & Hospital & $\begin{array}{l}\text { - FP may coordinate access to } \\
\text { hospitalization, but FP/patient relation } \\
\text { ship may be splintered in favour of } \\
\text { specialist/patient relationship; specialist } \\
\text { may differ for each hospitalization. }\end{array}$ \\
\hline $\begin{array}{l}\text { Family physician } \\
\text { institution }\end{array}$ & $\begin{array}{l}\text { Long-term-care } \\
\text { institution }\end{array}$ & $\begin{array}{l}\text { - FP/patient relationship may be splintered } \\
\text { and approach to care between FP and } \\
\text { providers may not be coordinated } \\
\text { effectively. }\end{array}$ \\
\hline
\end{tabular}


ed. Few understand that $40 \%$ of all new problems presenting to a family physician are undifferentiated and seldom develop into a definable diagnosis or problem (Starfield 1994; Rosser and Shafir 1998). The most efficient way to manage undifferentiated problems is "watchful waiting," which involves minimal investigation or referral. The focus is on reassuring patients and asking them to return for follow-up within an appropriate time period. This model of care only works when administered by an individual whom the patient knows and trusts. Lack of trust of the physician will cause the patient, fearing that he or she has a serious illness, to seek out other advice. Ninety percent of Ontario residents can name their family physician and recent surveys find the family physician to be the most trusted healthcare provider (Decima 1995; HayGroup 1997).

Unfortunately, current healthcare systems do not provide incentives or any support for family physicians to practise according to these four principles. The system today is excessively dependent upon emergency rooms, walk-in clinics and a plethora of potential contacts for care, provided by medical personnel who are unknown to the patient. This leads to undifferentiated problems being investigated extensively with $\mathrm{X}$-rays and laboratory tests and results in unnecessary consultations at an increased cost to the system. Improper problem management causes an unnecessary increase in anxiety for the patient. An understanding of the importance of the doctor/patient relationship and of continuity of care in creating the conditions for "watchful waiting" to manage undifferentiated problems is an essential component of affordable, quality care (Starfield 1998).

Currently, the fee-for-service funding model does not provide incentives for physicians to provide preventative care to a defined population or spend time providing community information or education. The practice population for individual physicians remains undefined and the emphasis has traditionally been on acute disease management. The system is steadily shifting away from institutional care towards increasing the patient's self-care abilities in the system. However, the lack of attention given to the primary-care system and to its role has created incentives that counter the desirable shifts to self-care (White, 


\section{TABLE 2: The Four Principles of Family Medicine}

\section{THE PATIENT-PHYSICIAN RELATIONSHIP IS CENTRAL TO THE ROLE OF THE FAMILY PHYSICIAN.}

Family physicians have an understanding and appreciation of the human condition, especially the nature of suffering and patients' response to sickness. They are aware of their strengths and limitations and recognize when their own personal issues interfere with effective care.

Family physicians respect the primacy of the person. The patient-physician relationship has the qualities of a covenant - a promise by physicians to be faithful to their commitment to patients' well-being, whether or not patients are able to follow through on their commitments. Family physicians are cognizant of the power imbalance between doctors and patients and of the potential for abuse of this power.

Family physicians provide continuing care to their patients. They use repeated contacts with patients to build on the patient-physician relationship and to promote the healing power of interactions. Over time, the relationship takes on special importance to patients, their families and physicians. As a result, family physicians become advocates for their patients.

\section{THE FAMILY PHYSICIAN IS A SKILLED CLINICIAN.}

Family physicians demonstrate competence in the patient-centred clinical method. They integrate a sensitive, skillful and appropriate search for disease. They demonstrate an understanding of patients' experience of illness (particularly their ideas, feelings and expectations) and of the effect of illness on patients' lives.

Family physicians use their understanding of human development and of family and other social systems to develop a comprehensive approach for promoting health and managing disease and illness in patients and their families.

Family physicians are also adept at working with patients to reach common ground on the definition of problems, goals of treatment and roles of physician and patient in management. They are skilled at providing information to patients in a manner that respects their autonomy and empowers them to take charge of their own healthcare and make decisions in their best interests.

Family physicians have an expert knowledge of the wide range of common problems of patients in the community and of less-common, but life-threatening and treatable emergencies in patients of all ages. Their approach to healthcare is based on the best scientific evidence available.

\section{THE FAMILY PHYSICIAN IS A RESOURCETO A DEFINED PRACTICE POPULATION.}

Family physicians view their practices as "populations at risk" and organize practice to ensure that patients' health is maintained, whether or not they visit the office. Such organization requires the ability to evaluate new information and its relevance to practice, knowledge and skills in order to assess the effectiveness of care provided by the practice, appropriate use of medical records and other information systems and the ability to plan and implement policies that will enhance patients' health.

Family physicians have effective strategies for self-directed, lifelong learning.

Family physicians have the responsibility to advocate public policy that promotes their patients' health.

Family physicians accept their responsibility in the healthcare system for wise stewardship of scarce resources. They consider the needs of both individuals and the community. 


\section{FAMILY MEDICINE IS A COMMUNITY-BASED DISCIPLINE.}

Family practice is based in the community and is strongly influenced by community factors. As members of communities, family physicians are able to respond to people's changing needs, to adapt quickly to changing circumstances and to mobilize appropriate resources to address patients' needs.

Clinical problems presenting to a community-based family physician are not pre-selected and are commonly encountered at an undifferentiated stage. Family physicians are skilled in dealing with ambiguity and uncertainty. They will see patients with chronic diseases, emotional problems, acute disorders (ranging from minor and self-limiting to life-threatening) and complex biopsychosocial problems. Finally, family physicians often provide palliative care to people with terminal diseases.

Family physicians care for patients in offices, hospitals (including emergency departments), other healthcare facilities and patients' homes. Family physicians see themselves as part of a community network of healthcare providers and are skilled at collaborating as team members or team leaders. They use referral to specialists and community resources judiciously.

Williams and Greenburg 1961). Table 3 illustrates that 25\% of all people in any given month are seen by a physician or receive home care, long-term care or hospital-based care. The sustainability of the system is dependent upon addressing the determinants of health to maintain and enhance the health status of the population and in-patient education to increase the level of self-care by patients. Incentives and an infrastructure to support health promotion and patient education are missing from the system. The majority of the funding rests with the parts of the healthcare system, namely consultants and hospitals, that are needed by only $1.01 \%$ of the people.

There is no current definition of services that patients should expect when attending a family physician. We believe that there needs to be a clearly defined list of services that the patient and physician know about and understand. Table 4 shows the scope of services that patients should expect from their family physician, as developed by the Provincial Coordinating Committee on Community and Academic Health Reform (PCCCAR). They have been adapted in keeping with the four principles of family medicine. It is unrealistic to expect that the defined comprehensive basket of services could be provided by any single physician. Physicians, therefore, need to be working in groups. In eastern Canada, for example, there are relatively few family physi- 
cians who practise in groups, and those that do tend to form very small group practices that are not conducive to providing comprehensive services to their practice populations. Current incentives promote a narrower scope of services, since high-volume, minor-problem, feefor-service practices are the most lucrative.

Canada has the best-trained family physician work force in the world and is valued for the scope of comprehensive services that family physicians are trained to provide. European countries tend to exclude general practitioners from functioning in hospitals or even working with other organizations in the community, whereas in Canada their role in in-hospital care and integration with other providers in the system is essential, especially in isolated smaller communities. The

\section{TABLE 3: Describing Illness in the Community: Illness for 1000 Persons During a One-Month Period}

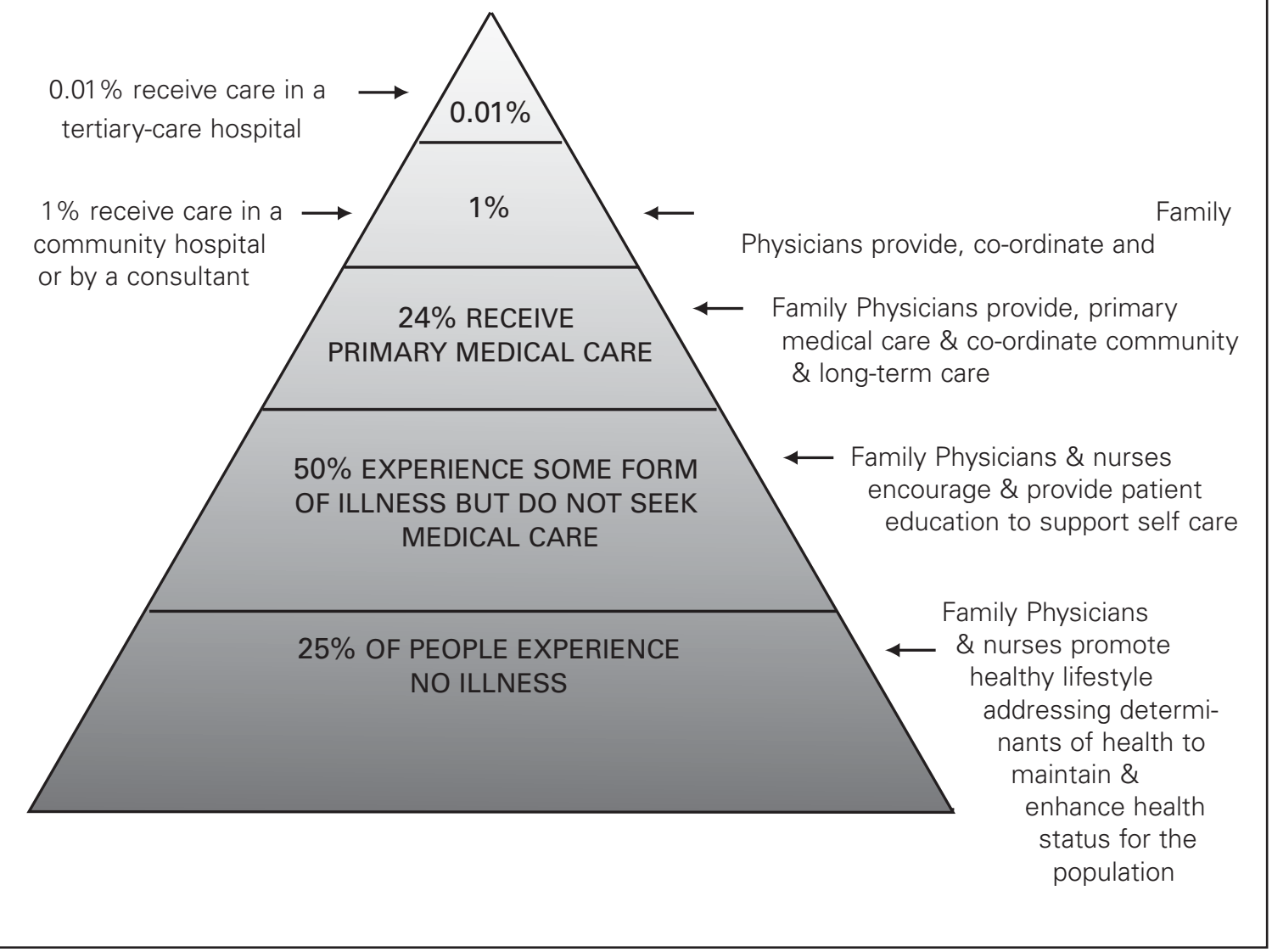


extended role that family physicians play is vital to our Canadian health system. Opportunities to practise by the four principles are being further aggravated by the growing rate of physician shortages. Increased workload and disincentives have combined to further demoralize family physicians throughout the province. It is alarming that family physicians are withdrawing from hospital care, long-term care and after-hour care and restricting their involvement in services such as obstetrics and mental health. It is time for actions that will reverse this trend.

\section{Proposal to Address Current Deficiencies}

The Ontario College of Family Physicians has embarked upon a process to define a more desirable profile for the family physician in the year 2000. This process has involved surveys of our membership and the structuring of a discussion document to address the perceived problems in the system. We believe that the successful implementation

\section{TABLE 4: Services to be Provided by all Family Physicians (PCCCAR Report, 1996)}

PRINCIPLE I:THE PHYSICIAN/PATIENT RELATIONSHIP IS ESSENTIAL.

- Advocacy for the patient in the system

- Primary mental-health care, including psychosocial counseling

PRINCIPLE II: THE FAMILY PHYSICIAN IS A COMPETENT CLINICIAN.

- Appropriate interventions for episodic illness and injury

- Primary reproductive care

- Diagnosis and initial/ongoing treatment of chronic illnesses

- Care of the majority of illnesses (in conjunction with consultants, if required)

- Supportive care in hospital, in home and in community-care facilities

PRINCIPLE III: THE FAMILY PHYSICIAN IS A RESOURCE TOTHE PRACTICE POPULATION.

- Health assessments

- Clinical evidence-based illness prevention and health promotion

- Education and support for self-care

- Support for those terminally ill

PRINCIPLE IV: THE FAMILY PHYSICIAN IS COMMUNITY-BASED.

- Arrangement for 24-hour/7-day a week response for urgent problems (to reduce work for emergency rooms)

- Service coordination and referral

- Coordination and access to rehabilitation

Source: Ontario College of Family Physicians 
of this plan would strengthen the primary-care base of the healthcare system in the province. A stronger, more coordinated primary-care system will facilitate development of an integrated secondary- and tertiary-care system. The desire for a "top down" process has been expressed by a number of groups (Leatt, Pink and Naylor 1996). We feel that family physicians, as the most trusted group of medical professionals, should be providing the leadership for "bottom-up" planning initiatives that will encourage public and stakeholder participation and support.

One widely accepted proposal is a system of "Patient Choice." We believe that every person in the province should choose one family physician and that the partnership should be formalized (Leopold, Cooper and Clancy 1996). Ninety percent of people in Ontario can identify their family physician of choice; however, owing to a shortage of family physicians throughout the province, many people are without a family physician or are unable to leave their current physician for fear of not finding a replacement. Table 5 demonstrates the strengths and weaknesses of a "Patient Choice System." We believe that there should be an adequate number of family physicians for each resident of the province to have access to a family doctor. Patients should have the right to move within the system if they or the physician feel their partnership is not functioning appropriately.

If family physicians are to provide a comprehensive basket of services, they need to work in group practices or practice networks (virtual groups). Physicians may wish to continue to practise in solo offices, but they would be linked into a group of other physicians ranging in size from seven to thirty who would be jointly responsible to provide the list of services in Table 4 . This would mean that any patient who selected a family physician in the province would be linked automatically into a system that would provide the basket of services. Urgent care would be provided by the members of the physician group on a 24-hour-a-day/7-days-per-week basis. This type of organization structure would require the support of excellent information systems so that physicians would have access to the health records of all the patients in the group practice or practice network. Groups 


\section{TABLE 5: Strengths/Weaknesses of Patient Choice}

\section{STRENGTHS OF FORMAL PATIENT CHOICE}

- Discourages double-doctoring

- Encourages a more equitable distribution of family physicians

- Discourages over-servicing of patients or duplication of investigation through a centralized record

- Provides more accurate demographic data because of constant updating

- Lends support to the four principles of family medicine

- Strengthens the ability to deliver continuity of care and monitors quality of care and health outcomes

- Provides a tool for coordinating healthcare, health promotion and illness prevention

- Encourages networking between family doctors and other healthcare providers

- Identifies the shortfall in physician resources in the province

- Attractive to patients because of the broader range of services available

- Ensures maintenance of comprehensive healthcare records

- Builds a trusting relationship not only with the physician but with other key healthcare providers

- Strengthens primary-care services by encouraging networking and decreasing isolation of individual practitioners

- Makes the gate-keeping role more feasible as the single family doctor, with whom the patient relates, has a better understanding of the resources individuals are accessing

- Provides physicians with the ability to advocate for the patient in a complex system

- Familiarizes people with and strengthens understanding of the role of the family physician making it easier for both to track and understand physician resource issues

- Improves communication within the institutions and, therefore, promotes the idea of integration

\section{WEAKNESSES OF FORMAL PATIENT CHOICE}

- Does not take into account marginalized disadvantaged populations

- Difficult to provide for special-need patients, i.e. mentally ill, homeless, seniors and the chronically ill, who may be better managed by the $\mathrm{CHC}$ model

- Favours the upper middle class

- There can be "cherry-picking" by doctors

- May exclude some physicians with certain styles or ethnic groups in their practice

- Could promote a two-tier system, i.e. those opting for physician practice vs. those who do not

- There are unresolved issues around commuters and people who live in two or three different places during the year

- The inappropriate use of emergency departments and walk-in clinics could continue if there is no mechanism for patient accountability

- There may not be enough physicians to actually make it work

- As a practice ages, the requirement for service for that population will increase and make the practice more burdensome

- Physicians may not like the lack of freedom to practise wherever they choose

- There is no current mechanism for accountability of patients

- There may be an increase in resources needed to deal with telephone work, patient demands and expectations, and the physician will be responsible for changing patient behavior

- It is recommended that patients not change physicians more than three or four times per year

- Information technology costs and workload increases would need to be addressed 
should have a minimum of seven physicians (except in isolated areas) to a maximum of thirty physicians. The NHS British general-practice system has recently formed groups of 50 general practitioners to provide service in a region and has over 500 such groups functioning. They are supplied with an interconnected information technology system and each group runs internal quality-assurance programs.

The lack of a coordinated, centralized health record is a major problem of the current system. From a patient perspective, the health record should be held in the family physician's office. The family physician would be responsible for maintaining a comprehensive health record for each patient. All providers in the system with whom the patient had contact would be required to forward copies of all reports and associated information from that contact to the family physician. Information technology will be a necessary tool to support this responsibility. This strategy is now being utilized in the United Kingdom with even social services adding information to the GP group.

The real or virtual group model lends itself to physicians working in collaboration with other healthcare providers. Provision of the basket of services could be greatly enhanced by the use of nurse practitioners and family-practice nurses working in collaboration with family physicians to provide preventative and chronic care, by the use of midwives to augment the provision of obstetrical, prenatal and postnatal care and by the collaboration that could occur with community access and hospital-in-the-home services. By having electronically connected groups, each component could be integrated both at a primary medical-care and community level and with secondary and tertiary levels.

We believe these steps would result in a well-organized, albeit basic, primary-care system that would provide the foundation upon which to build an integrated system. With the key role of the family physician as the coordinator of care throughout the continuum of service delivery recognized, access to affordable quality care will be enhanced and the cost of duplication of services will be reduced (see Table 6). 


\begin{tabular}{|c|c|c|c|}
\hline $\begin{array}{l}\text { SYSTEM } \\
\text { ACCOUNTABILITY }\end{array}$ & $\begin{array}{l}\text { FAMILY } \\
\text { PHYSICIAN } \\
\text { ACCOUNTABILITY }\end{array}$ & $\begin{array}{l}\text { FAMILY } \\
\text { MEDICINE } \\
\text { SYSTEM }\end{array}$ & $\begin{array}{l}\text { MAINTENANCE OF } \\
\text { DOCTOR/PATIENT RELATIONSHIP }\end{array}$ \\
\hline \multirow{8}{*}{$\begin{array}{l}\text { Chief of } \\
\text { Family Medicine } \\
\text { monitors quality } \\
\text { of care through } \\
\text { the continuum } \\
\text { of family-medicine } \\
\text { services, or there } \\
\text { will be a designat- } \\
\text { ed Chief of } \\
\text { Community } \\
\text { Family Physicians } \\
\text { Services. }\end{array}$} & \multirow{8}{*}{$\begin{array}{l}\text { Family physician } \\
\text { provides and } \\
\text { co-ordinates access } \\
\text { to and monitors } \\
\text { care for his/her } \\
\text { patients. }\end{array}$} & $\begin{array}{l}\text { Family practice } \\
\text { visit }\end{array}$ & $\begin{array}{l}\text { FP/patient relationship maintained and } \\
\text { care may be enhanced through FP/RN } \\
\text { team approach to care delivery. }\end{array}$ \\
\hline & & $\begin{array}{l}\text { FP group or } \\
\text { practice net- } \\
\text { work or } \mathrm{CHC}\end{array}$ & $\begin{array}{l}\text { FP or FP/RN team supported by a group } \\
\text { or practice network to deliver } 24 \text {-hour/ } \\
\text { 7-day-per-week access to the full contin- } \\
\text { uum of services on a regular or urgent- } \\
\text { needs basis. FP/patient relationship } \\
\text { maintained. }\end{array}$ \\
\hline & & Consultant & $\begin{array}{l}\text { FP coordinates access to consultants } \\
\text { and maintains records with the relation- } \\
\text { ship being consultant to FP and patient. } \\
\text { FP/patient relationship maintained. } \\
\text { Shared-care model used. }\end{array}$ \\
\hline & & $\begin{array}{l}\text { INTEGRATED } \\
\text { DELIVERY } \\
\text { SERVICE }\end{array}$ & $\begin{array}{l}\text { MAINTENANCE OFTHERAPEUTIC } \\
\text { RELATIONSHIP }\end{array}$ \\
\hline & & $\begin{array}{l}\text { Emergency } \\
\text { department }\end{array}$ & $\begin{array}{l}\text { FP or FP group/network coordinates } \\
\text { access to emergency care for } \\
\text { urgent/emergent problems. FP/patient } \\
\text { relationship maintained. }\end{array}$ \\
\hline & & $\begin{array}{l}\text { Home care/ } \\
\text { community } \\
\text { services }\end{array}$ & $\begin{array}{l}\text { FP or FP/RN team works closely with } \\
\text { home care/community services to } \\
\text { coordinate care. }\end{array}$ \\
\hline & & Hospital & $\begin{array}{l}\text { FP or FP/RN team works closely with } \\
\text { hospital-based consultant and RNs to } \\
\text { coordinate inpatient care and develop } \\
\text { discharge plan. }\end{array}$ \\
\hline & & Long-term care & $\begin{array}{l}\text { FP or FP/RN team works closely with } \\
\text { LTC staff to coordinate care. }\end{array}$ \\
\hline
\end{tabular}

Integration at a secondary-care level could be achieved by psychiatrists, pediatricians and obstetricians being allocated according to the population base. These consultants would work to support one or more groups of family-physician providers. An excellent model on which to build such integration has been developed in a proposal for 
shared care in psychiatry (Kates et al. 1997) and could be extended to include the provision of medical, surgical and pediatric services. The secondary-care providers would then be responsible for involvement with tertiary-care providers and for facilitating patient care at tertiarycare centres. Not only would secondary-care providers act as consultants, but they would also work to improve the skills and knowledge of the family physicians and other primary-care providers. The secondary-care model would enhance the concept of the patient moving between caregivers in a "seamless" system.

To encourage integration with the broader healthcare system, every family physician should be an active staff member of his or her local hospital. Evidence from the College of Physicians and Surgeons of Ontario (CPSO) suggests that practising in a group, holding certification or membership at the College of Family Physicians of Canada (CFPC) and being attached to a hospital staff reduces the risk of a physician being judged incompetent in the Peer Assessment Program (McCauley et al. 1990). How quality improvement would be facilitated at the local level is contentious. One suggested model included the hospital Chief of Family Practice being responsible for facilitating/ implementing quality-improvement programs for community physicians. Another suggestion is the formation of a regional health authority that has a family physician as facilitator for the region, responsible for quality improvement. A third suggestion is to appoint a facilitator physician for every 50 physicians, accountable to a provincial supervisory body for quality improvement. A potential model of governance that integrates family medicine with hospital and community-based services is outlined in Table 7. Full horizontal integration of hospital and community-based services with strong linkages to the familymedicine system would be a feasible model in many communities.

To overcome deficiencies in the current system and the lack of incentive to practise the four principles of family medicine, $79 \%$ of our membership support the concept of a blended funding model (Table 8). This would modify incentives and provide accountability for a basket of comprehensive services offered to a specific patient population within a "Patient Choice of Physician System." 


\section{TABLE 7: Regional Integrated Delivery System: A Community Model}

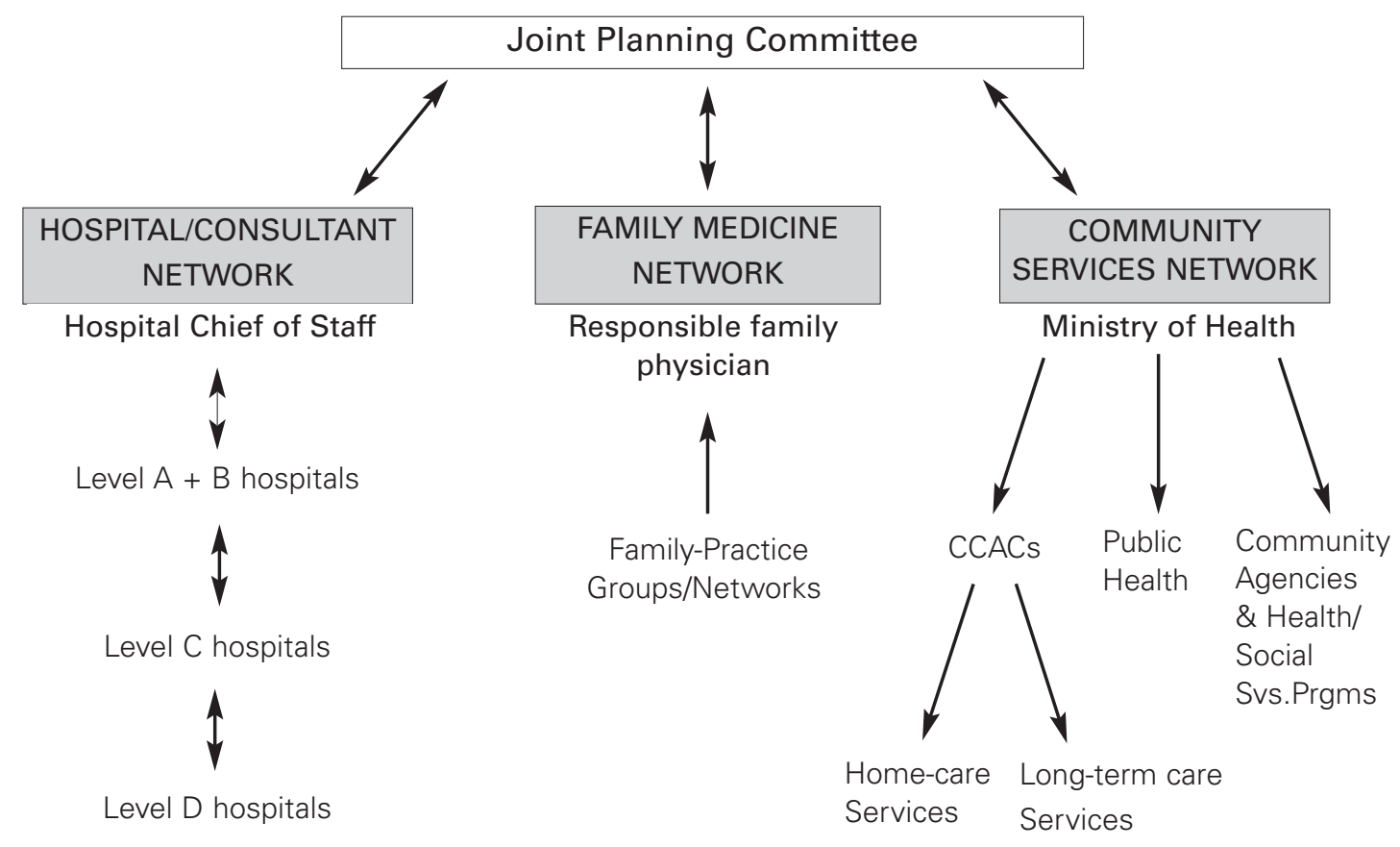

From the viewpoint of the Ontario College of Family Physicians, the primary medical-care system has been taken for granted for too long. The result is a fairly rapid deterioration in the ability of the primary-care sector to provide appropriate and accessible services to the population. Strong action is necessary to overcome deficiencies identified in the current system. Politicians have been reluctant to take these steps because they carry considerable political risk, in that a number of interest groups are likely to protest loudly. In addition, the public is likely to perceive change as yet a further attack on the healthcare system in order to save money. The proposals outlined in this paper are likely to be revenue-neutral, although some investment in information systems and reorganization will be required. In relative terms, there will be cost savings to the system. This will occur as a result of reduction in the utilization of secondary- and tertiary-care services. However, this may be offset by increased spending in the primary-care sector. With family physicians assuming 24-hour responsibility for urgent primary 


\section{HealthcarePapers}

\section{TABLE 8: Executive Summary of a Proposal for a Blended Funding Mechanism (The College of Family Physicians of Canada)}

In July 1992, the College of Family Physicians of Canada (CFPC) released the document "A Proposal for a Blended Funding Mechanism." With the rapidly changing economic environment as a result of mounting government debt, it is timely to reassess current methods of physician remuneration. Time is of the essence if we are to avoid being forced into payment mechanisms that are unfair to physicians, lack incentive to improve quality of care and, in the end, discourage physicians from providing an appropriate volume of comprehensive services needed by their patients. The CFPC proposal rewards family physicians more appropriately for the services they provide and, in addition, will improve quality of care through encouragement of continuing medical education (CME), quality-assurance programs, maintenance of certification, research, teaching and maintenance of hospital privileges. The CFPC plan is also less volume-driven, yet provides incentives to maintain appropriate levels of service. With the plan's emphasis on ambulatory care, comprehensive care and continuity of care, a decrease in overall healthcare costs can be achieved by avoiding unnecessary duplication of services and the higher cost of institutional care. The CFPC proposal has four components.

\section{A. BASE}

A base salary would be paid for a minimum number of office hours per week and prorated for fewer hours of work. Also, an additional number of work units would be guaranteed within this time frame. Included in the calculation of the base would be payment for:
(i) Holidays
(iii) Pension contribution
(ii) $\mathrm{CME}$
(iv) Insurance - life, disability, medical/dental

\section{B. OVERHEAD COSTS}

Overhead costs would be separated to ensure that income and expense are readily transparent to both the public and the physician. This section includes all cost related to:
(i) Rent
(iii) Legal and audit
(ii) Equipment
(iv) Staffing

\section{NON-VOLUME MODIFIERS}

Incentives would be paid to encourage the participation of physicians in needed areas of care:
(i) Isolation allowance
(viii) Administration and health care planning
(ii) Obstetrics
(ix) Acquisition \& maintenance of special skills
(iii) Maintenance of certification
(x) Ambulatory care
(iv) Teaching
(xi) Research
(v) On-call
(xii) Quality assurance programs
(vi) Nursing homes/residential care (xiii) Special community needs
(vii) Hospital practice

\section{VOLUME MODIFIERS}

- A numerical value is placed on individual work units. As each physician accumulates a total number of work units, he/she would fit into a specific category, each having a dollar value. Work units could be equivalent to the resource-based relative-value fee units each province is evolving, i.e.,

$$
0-1000 \text { units }=\$ A / 1000-2000 \text { units }=\$ B / 2000-3000 \text { units }=\$ C
$$

- No increase would be given over an agreed number of work units, or

- A capitation type of remuneration could be used based on a patient roster.

In summary, the CFPC plan is a comprehensive proposal that allows for flexibility and pluralism. It promotes continuity, comprehensiveness and availability of care. It provides incentives for productivity and yet is not directly volume-driven. It encourages the family physician to deliver appropriate high quality healthcare. It allows the family physician to assume the responsibility both for coordination of services and for the appropriate use of these services. It allows the family physician to be an effective team player within the multidisciplinary approach to healthcare. 
care, demands on emergency rooms should be sharply reduced, resulting in more savings.

\section{Conclusion}

The Ontario College of Family Physicians is embarking upon a process to involve all stakeholders in an open discussion about taking steps to support and strengthen family physicians' abilities to provide excellent primary care. The proposed major reorganization of the primary healthcare system would both benefit the population and provide the basis on which system integration will be feasible. This proposal will go a long way to integrate community and secondary-care services. Implementation of this plan would strengthen what is widely viewed as one of the best healthcare delivery systems in the world.

\section{References}

College of Physicians and Surgeons of Ontario (CSPO). 1999. Annual Licensing Registration 1950-98. Toronto. Decima Research. 1995. A Decima research report to the Ontario College of Family Physicians.

Hay Group. 1997. A Vision of Ontario's Health Services System. Report to Health Services Restructuring Commission.

Kates, N., M. Craven, J. Bishop, T. Clinton, et al. 1997. Shared Mental Health Care in Canada. A report from the joint committee of the Canadian Mental Health Association and the College of Family Physicians of Canada.

Leatt, P., G. Pink and D. Naylor. 1996. Integrated Delivery Systems: Has Their Time Come in Canada. Canadian Medical Association Journal 154(6):803-9.

Leopold, N., J. Cooper and C. Clancy. 1996. Sustained Partnerships in Primary Care. Journal of Family Practice 42(2): 129-37.

McCauley, R. G., U.M. Paul, G.H. Morrison, R.E. Boeuett and C.H. Goldsmith. 1990. Five Year Results of the Peer Assessment Program of The College of Physicians and Surgeons of Ontario. Canadian Medical Association Journal 143(11): 1193-99.

Ontario College of Family Physicians (OCFP). 1999a. Inaugural address from the president. Chapter 11:1. - 1999b. Two Tier, Multilayered Health Care System. Toronto (available on OCFP website www.ctpc.ca/ocfp/).

- 1999c. Centres of Excellence in Family Medicine. Toronto (available on OCFP website www.cfpc.ca/ocfp/). Rosser, W., and S. Shafir. 1998. Evidence-Based Family Medicine. BC Decker Hamilton.

Starfield, B. 1994. Is Primary Care Essential? Lancet 344:1129-33.

- 1998. Primary Care: Balancing Health Needs, Services and Technology. New York: Oxford University Press.

PCCCAR - Subcommittee on Primary Health Care of the Provincial Coordinating Committee on Community and Academic Health Science Centre Relations. 1996. New Directions in Primary Health Care. Appendix 3.

White, K.L., T.F. Williams and B.G. Greenburg. 1961. The Ecology of Medical Care. New England Journal of Medicine 265 